\title{
MODELING HIGH-PRESSURE CHAR OXIDATION USING LANGMUIR KINETICS WITH AN EFFECTIVENESS FACTOR
}

\author{
J. HONG, W. C. HECKER AND T. H. FLETCHER \\ Chemical Engineering Department \\ Brigham Young University \\ Provo, UT 84602, USA
}

\begin{abstract}
The global $n$th order rate equation has been criticized for lack of theoretical basis and has been shown to be inadequate for modeling char oxidation rates as a function of total gas pressure. The simple Langmuir rate equation is believed to have more potential for modeling high pressure char oxidation. The intrinsic Langmuir rate equation is applied to graphite flake oxidation data and agrees well with reaction rates at three temperatures over the entire range of oxygen pressure (1-64 atm). It also explains the change of reaction order with temperature.

In this work, the intrinsic Langmuir rate equation is combined with (1) an effectiveness factor to account for pore diffusion effects and (2) a random pore structure model to calculate effective diffusivity.

The resulting model is able to predict the reaction rates of large $(c a .8 \mathrm{~mm})$ coal char particles as a function of gas velocity, total pressure, oxygen partial pressure, oxygen mole fraction, initial particle size, and gas temperature. This approach is also able to correlate the particle burnouts of pulverized $(70 \mu \mathrm{m})$ coal char particles in a drop tube reactor as a function of total pressure, oxygen mole fraction, gas and wall temperatures, and residence time. The ability of the model to correlate data over wide range of temperature and pressure is promising.
\end{abstract}

\section{Introduction}

A global $n$th order rate equation is often used to describe kinetics of char oxidation at typical industrial boiler temperatures [1-3]:

$$
q_{\mathrm{rxn}}=A \exp \left(-E_{\mathrm{obs}} / R T\right) P_{\mathrm{os}}^{n}
$$

The global $n$th order rate equation has been criticized for lack of theoretical basis and for inadequately predicting rates over wide ranges of experimental conditions, especially for high-pressure char oxidation modeling [3-5]. Attempts to use the global $n$th order rate equation to explain high-temperature coal char oxidation rates had to use pressure-dependent activation energies, which was not a realistic approach $[3,4]$. Fundamental studies show that the carbon-oxygen reaction involves chemisorption, oxygen surface diffusion, and desorption of surface oxygen complexes [6-8]. The $n$th order rate equation fails to reflect the adsorption-desorption nature of this reaction. A more mechanistically meaningful representation of the intrinsic reaction rate is a Langmuir-Hinshelwood form [6,9], which in its simplest form becomes the Langmuir rate equation:

$$
r_{\text {in }}^{\prime \prime \prime}=k_{1} P_{\mathrm{O}_{2}} /\left(1+K P_{\mathrm{O}_{2}}\right)
$$

where $k_{1}$ and $K$ are two kinetic parameters. It should be noted that there are different possible mechanisms leading to equation 2. The discussion in this study is general and independent of mechanisms. The Langmuir rate equation can be rewritten as

$$
1 / r_{\mathrm{in}}^{\prime \prime \prime}=1 /\left(k_{1} P_{\mathrm{O}_{2}}\right)+1 / k_{0}
$$

where $k_{0}$ is equal to $k_{1} / K$.

In an attempt to treat effects of pressure, Essenhigh proposed a so-called second effectiveness factor [10] to account for the internal combustion. The second effectiveness factor was calculated from the power index of the normalized density-diameter relationship $[5,10,11]$ :

$$
\begin{gathered}
\varepsilon=1+\alpha / 3 \\
\rho / \rho_{0}=\left(d / d_{0}\right)^{a}
\end{gathered}
$$

The second effectiveness factor approach has several weaknesses: First, the second effectiveness factor approach requires density and diameter data, which are often not available a priori, in order to determine the power index $\alpha$. Hence, this method is not truly predictive in nature. Second, the power index $\alpha$ is very difficult to determine accurately, since it can vary over several orders of magnitude (reported values of $\alpha$ are around 1 for high temperature char oxidation and are $10^{4} \sim 10^{5}$ for low temperature char oxidation [10]). Third, this approach assumes that the power index $\alpha$ remains constant throughout the whole range of burnout. In a typical pulverized char combustor, a char particle travels through different zones of the reactor and 
interacts with different combustion environments, leading to different burning modes (corresponding to $\alpha$ between zero and infinity). It is therefore desirable to develop an alternative approach to account for pore diffusion effects for the Langmuir rate equation.

\section{Theoretical}

In the approach proposed here, the effectiveness factor is used to account for effects of pore diffusion on the Langmuir rate equation:

$$
r_{\text {obs }}^{\prime \prime \prime}=\eta k_{1} P_{\text {os }} /\left(1+K P_{\text {os }}\right)
$$

It has been established that the effectiveness factor for spherical particles can be approximately predicted by $[12-14]$

$$
\begin{array}{r}
\eta=\left[\operatorname{coth}\left(3 M_{\mathrm{T}}\right)-\left(3 M_{\mathrm{T}}\right)^{-1}\right] / M_{\mathrm{T}} \\
M_{\mathrm{T}}=\frac{d_{\mathrm{p}}\left(\frac{v_{\mathrm{O}} k_{1} R T_{\mathrm{P}}}{2 D_{\mathrm{e}}}\right)^{0.5} \frac{K P_{\mathrm{os}}}{1+K P_{\mathrm{os}}}}{} \\
{\left[K P_{\mathrm{os}}-\ln \left(1+K P_{\mathrm{os}}\right)\right]^{-0.5}}
\end{array}
$$

\section{Model Description}

\section{Kinetics and Pore Diffusion}

This model treats the energy equation and external boundary layer diffusion in a manner similar to that used by Mitchell et al. [15], but uniquely treats the particle reaction rate per external surface area with an intrinsic Langmuir rate equation and an effectiveness factor:

$$
\begin{aligned}
q_{\mathrm{rxn}} & =M_{\mathrm{c}}\left(V_{\mathrm{p}} / S_{\mathrm{e}}\right) r_{\mathrm{obs}}^{\prime \prime \prime} \\
& =M_{\mathrm{c}}\left(d_{\mathrm{p}} / 6\right) \eta k_{1} P_{\mathrm{os}} /\left(1+K P_{\mathrm{os}}\right)
\end{aligned}
$$

where $d_{\mathrm{p}} / 6$ converts the reaction rate from a volumetric basis into external surface area basis, and $M_{\mathrm{c}}$ converts the molar rate into mass rate.

The resulting model is called the high-pressure carbon burnout kinetics model, or HP-CBK model, and includes the changes in reactivity at late burnout proposed by Hurt et al. [16]. However, due to lack of data at high pressure, the changes in reactivity at late burnout are not shown in this paper.

\section{Boundary Layer Diffusion}

In this study, the correlations for Sherwood number and Nusselt number are [17]

$$
\begin{aligned}
& S h=2.0+0.60 R e^{1 / 2} S c^{1 / 3} \\
& N u=2.0+0.60 \operatorname{Re}^{1 / 2} \operatorname{Pr}^{1 / 3}
\end{aligned}
$$

These correlations allow the HP-CBK model to be used for large-particle char oxidation. The boundary layer diffusion is modeled in a manner similar to that used by Mitchell et al. [15], taking Stefan flow into account [18].

A $\chi$ factor is often used as a criterion of whether the combustion rate is controlled by boundary layer diffusion [1]:

$$
\chi=q_{\text {act }} / q_{\max }
$$

where $q_{\text {act }}$ is the actual rate of reaction, and $q_{\text {max }}$ is the maximum rate reaction limited by boundary layer diffusion. When the $\chi$ factor is close to unity (say 0.95 ), the combustion rate is controlled by boundary layer diffusion; otherwise, chemical kinetics (often with pore diffusion effects) must be considered.

\section{Effective Diffusivity}

The major obstacle to calculating pore diffusion effects is the accurate determination of the effective diffusivity. In general, both bulk and Knudsen diffusion may contribute to the rate of mass transport within the porous structures of the char. The combined effects of these two diffusion mechanisms can be described by the combined diffusivity $D[19,20]$ :

$$
D=\left(1 / D_{\mathrm{AB}}+1 / D_{\mathrm{K}}\right)^{-1}
$$

The Knudsen diffusivity can be calculated from classical kinetic theory [19]:

$$
D_{\mathrm{K}}=9.70 \times 10^{3} r_{\mathrm{p}}(T / 32)^{1 / 2}
$$

where $D_{\mathrm{K}}$ is in $\mathrm{cm}^{2} / \mathrm{s}$, and $r_{\mathrm{p}}$ is the pore radius in centimeters.

The random pore model is used to convert the diffusivity to the effective diffusivity. This model was originally developed for catalytic pellets containing a bi-disperse pore system $[21,22]$. The resultant expression for the effective diffusivity may be written

$$
\begin{aligned}
D_{\mathrm{e}}= & \varepsilon_{\mathrm{M}}^{2} D_{\mathrm{M}}+\left(\varepsilon-\varepsilon_{\mathrm{M}}\right)^{2} \\
& \left(1+3 \varepsilon_{\mathrm{M}}\right)\left(1-\varepsilon_{\mathrm{M}}\right)^{-1} D_{\mu}
\end{aligned}
$$

where $D_{\mathrm{M}}$ and $D_{\mu}$ are the combined diffusivity in macro- and micropores, respectively, and $\varepsilon$ and $\varepsilon_{\mathrm{M}}$ are the total porosity and macroporosity of the particle. The random pore model has four parameters: $\varepsilon, \varepsilon_{\mathrm{M}}, r_{\mathrm{p} 1}$ (macropore radius) and $r_{\mathrm{p} 2}$ (micropore radius). The porosity of a char can be calculated and is therefore not an adjustable parameter.

\section{Model Evaluation}

The HP-CBK model, using the Langmuir rate equation, the effectiveness factor and the random pore model, was evaluated by comparison with three sets of pressure-dependent reactivity data: (1) graphite flakes [23]; (2) large coal char particles [24]; and 


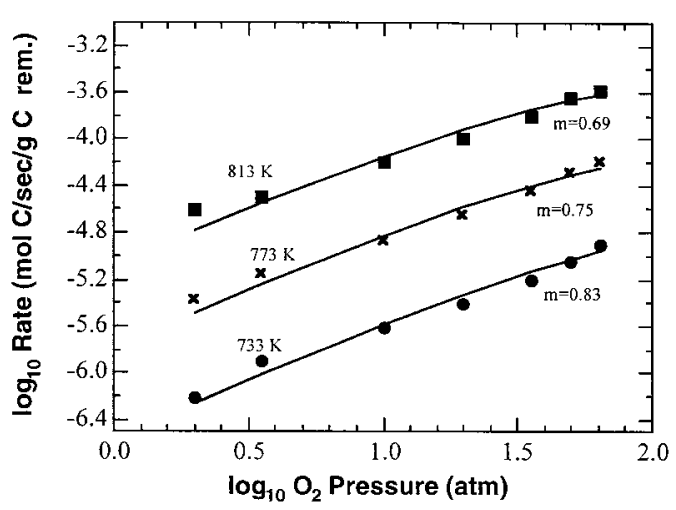

FIG. 1. Comparison of HP-CBK predictions of carbon reactivity with graphite flake data [21] obtained as a function of $P_{\mathrm{O}_{2}}$ and $T_{\mathrm{p}}$.

(3) pulverized coal char particles [3,4]. Additional modeling details are given by Hong [14].

\section{Graphite Flake Experiments}

Ranish and Walker [23] measured the oxidation rates of some highly crystalline graphite flakes in pure oxygen at pressures from 1 to 64 atm and temperatures between 733 and $842 \mathrm{~K}$. They observed that the reaction order decreased from 0.83 to 0.69 as reaction temperature increased from 733 to 813 K. Banin et al. [25] also observed that the reaction order of char oxidation decreased with temperature.
These observations contradict the prediction of Essenhigh [10], which suggested that the reaction order should increase with increased temperature at constant oxygen pressure.

Under the conditions of these experiments, boundary layer diffusion resistance can be safely neglected. The Langmuir rate equation was applied to these rate data (see Fig. 1). Fig. 1 shows that the model agrees well with the reaction rates at three temperatures over the entire range of oxygen pressure. The Langmuir rate equation also captures the change of observed reaction order with temperature. Note that the reaction orders (the $m$ values in Fig. 1) are the averaged slopes of the lines in Fig. 1. Since the graphite flakes used in these experiments are non-porous, the rate equation can be expressed in a slightly different form:

$$
r_{\text {in }}^{\prime}=k{ }_{1}^{\prime} P_{\mathrm{O}_{2}} /\left(1+K P_{\mathrm{O}_{2}}\right)
$$

where $r_{\text {in }}^{\prime}$ is in $\mathrm{g} \mathrm{C} /(\mathrm{g} \mathrm{C}$ remaining $) / \mathrm{s}$, and $k_{1}^{\prime}$ is in $\mathrm{g}$ $\mathrm{C} /(\mathrm{g} \mathrm{C}$ remaining)/atm/s. The best-fit kinetic constants are listed in Table 1 . Notice that $E_{0}=\left(E_{1}-\right.$ $E)=(51.1-10.1)=41.0 \mathrm{kcal} / \mathrm{mol}$, which is less than $E_{1}(51.1 \mathrm{kcal} / \mathrm{mol})$.

\section{Large Coal Char Experiments}

The reactivities of large Pittsburgh char particles were measured [24] in the high-pressure controlled profile (HPCP) drop-tube reactor [3] using a cantilever balance attachment (CBA) [26]. Gas temperatures were measured by a type-S thermocouple located about $1.2 \mathrm{~cm}$ above the supported particle.

TABLE 1

Parameters used in modeling experimental data

For Ranish and Walker data [23]:

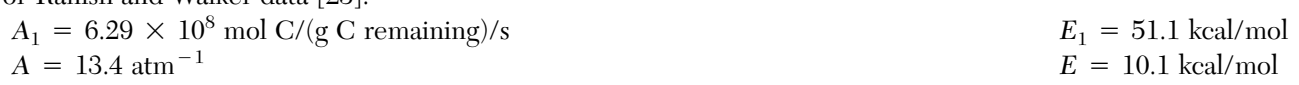

Non-porous graphite flakes

No $\mathrm{CO} / \mathrm{CO}_{2}$ product ratio is assumed since reaction temperatures are controlled.

For Mathias data [25]:

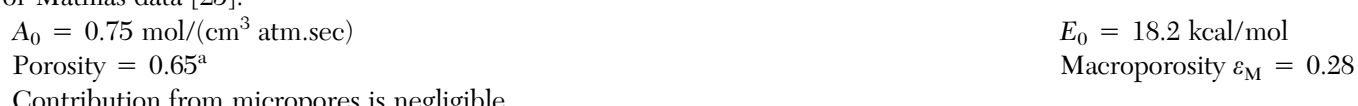

Contribution from micropores is negligible.

Macropore radius is large enough so that Knudsen diffusion is negligible.

$\mathrm{CO} / \mathrm{CO}_{2}=4.0 \times 10^{4} \exp \left(-30000 / 1.987 / \mathrm{T}_{\mathrm{p}}\right)^{\mathrm{a}}$

For Monson data [4]:

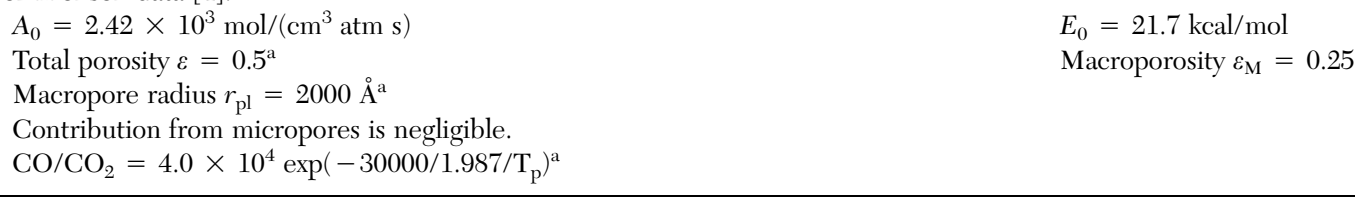

${ }^{a}$ Values calculated from experimental measurements and/or preset in modeling. Other parameters are adjustable variables and their values are determined by least square fitting. 
TABLE 2

Conditions of the large particle experiments

\begin{tabular}{llllllr}
\hline & $\begin{array}{c}P_{\text {total }} \\
(\mathrm{atm})\end{array}$ & $\begin{array}{c}P_{\mathrm{O}_{2}} \\
(\mathrm{~atm})\end{array}$ & $\begin{array}{c}V_{\mathrm{g}} \\
(\mathrm{m} / \mathrm{s})\end{array}$ & $\begin{array}{c}T_{\mathrm{g}} \\
(\mathrm{K})\end{array}$ & $\begin{array}{c}d_{\mathrm{po}} \\
(\mathrm{mm})\end{array}$ & $Y_{\mathrm{O}_{2}}$ \\
\hline Base & 0.85 & 0.18 & 0.32 & 1050 & 8.00 & $21 \%$ \\
1 & $\mathrm{a}$ & & 0.08 & & & \\
2 & & & 1.28 & & & $14 \%$ \\
3 & 0.85 & 0.12 & & & & $7 \%$ \\
4 & 0.85 & 0.06 & & & & $21 \%$ \\
5 & 3 & 0.63 & & & & $21 \%$ \\
6 & 5 & 1.05 & & & & $7.2 \%$ \\
7 & 3 & 0.21 & & & 6.35 & \\
8 & 5 & 0.21 & & & 9.16 & \\
9 & & & & & & \\
10 & & & & 1200 & & \\
11 & & & & 825 & & \\
$12^{\mathrm{b}}$ & & & & & & \\
\hline
\end{tabular}

\footnotetext{
${ }^{\mathrm{a}} \mathrm{A}$ blank cell means that the value is maintained at the baseline condition.

${ }^{\mathrm{b}}$ Condition excluded due to prolonged heating-up period.
}

The chars were prepared from Pittsburgh coal (38\% volatile matter, $11 \%$ ash) in $\mathrm{N}_{2}$ at a gas temperature of $1050 \mathrm{~K}$, a gas velocity of $0.32 \mathrm{~m} / \mathrm{s}$, a gas pressure of $0.85 \mathrm{~atm}$, and a residence time of $32 \mathrm{~s}$. Most char particles used in the oxidation experiments had an initial mass of $0.11 \mathrm{~g}$ (corresponding to $8 \mathrm{~mm}$ diameter). A baseline condition was selected, and a parametric set of experiments was conducted by varying one (or sometimes two) of the six variables $\left(V_{\mathrm{g}}, P_{\mathrm{O}_{2}}, P_{\mathrm{tot}}, d \mathrm{p}_{0}, y_{\mathrm{O}_{2}}, T_{\mathrm{g}}\right)$, as shown in Table 2. Five runs were performed at each of these 13 conditions to reduce random errors and to determine the repeatability.

The particle center temperatures were measured for three conditions (base condition, and conditions 11 and 12) using a type-S thermocouple inserted in a small hole drilled approximately to the center of the particle and attached to the particle with a small amount of epoxy. For all of these three conditions, the temperature profiles all show a characteristic drop near the end of combustion (at about $85 \%$ dry ash free [daf] burnout). This temperature drop is consistent with the near-extinction behavior observation by Hurt and Davis [27]. The main interest of this study is the reaction rates before the near-extinction stage and, therefore, average reactivities were determined for the $10 \%-70 \%$ burnout region. In addition, the temperature profile of condition 12 $\left(T_{\mathrm{g}}=825 \mathrm{~K}\right)$ showed that the particle was heating up continuously until the near-extinction behavior began. This prolonged heating period is due to the very low gas temperature and the large size of the particle, and it makes this condition different from all other conditions. Therefore, this one condition was excluded in this study.

The particle reaction rates were originally reported as normalized mass rates $(d U / d t)$ versus burnout (B). These rates were converted to rates based on external surface area as follows: (1) For each experimental condition, three values were obtained from the $d U / d t$ curve at $\mathrm{B}=20 \%, 40 \%$, and $60 \%$, respectively. (2) The mass release rates $(\mathrm{dm} /$ $d t$ ) were calculated from the normalized mass release rates $(d U / d t)$. (3) The values of diameter at different burnout were estimated assuming that the density remains constant with burnout. This assumption is supported by the measurements by Mathias [23]. (4) The reaction rates based on the external surface area were calculated from the mass release rates $(d m / d t)$ and the external surface area $\left(\pi d_{\mathrm{p}}^{2}\right)$. It was found that for each condition the reaction rates based on the external surface area are almost identical at burnouts of $20 \%, 40 \%$, and $60 \%$, indicating a constant burning rate between $10 \%$ and $70 \%$ burnout. For each condition, the reaction rates at these three burnouts were averaged to yield a characteristic reactivity, which was used in model evaluation.

The values of $\chi$ factor were calculated for all of the conditions, assuming the $\mathrm{CO} / \mathrm{CO}_{2}$ product ratio can be estimated using an empirical Arrhenius correlation taken from Hurt and Mitchell [2]:

$$
\begin{aligned}
\mathrm{CO} / \mathrm{CO}_{2}= & 4.0 \times 10^{4} \\
& \exp \left(-30000 / 1.987 / T_{\mathrm{p}}\right)
\end{aligned}
$$

According to this correlation, $87 \%$ of the carbon is converted to $\mathrm{CO}_{2}$ and $13 \%$ to $\mathrm{CO}$ at $1200 \mathrm{~K}$. This expression for the $\mathrm{CO} / \mathrm{CO}_{2}$ ratio was chosen so that the particle temperatures predicted by the HP-CBK model matched the limited number of measured particle center temperatures. It was found that the values of $\chi$ factor ranged from $0.2-0.7$, indicating that combustion did not occur in zone III. If the $\mathrm{CO} / \mathrm{CO}_{2}$ product ratio is chosen so that more carbon is converted to $\mathrm{CO}$, the values of the $\chi$ factor would be even smaller and farther away from zone III conditions. It was therefore concluded that these reaction rates are not controlled by boundary layer diffusion, and hence chemical kinetics and pore diffusion have to be considered in modeling these data.

The HP-CBK model was used to predict the characteristic reactivities at all 12 conditions with a single set of kinetic and pore structure parameters. The particle sizes used in the HP-CBK model were those at $40 \%$ burnout since the characteristic reactivities represent the averaged reactivities over $10 \%$ to $70 \%$ burnout. The particle temperatures were calculated assuming thermal equilibrium between the particle and the environment $\left(T_{\mathrm{g}}\right.$ and $\left.T_{\mathrm{w}}\right)$ through convection, conduction, and heat generation from reaction 

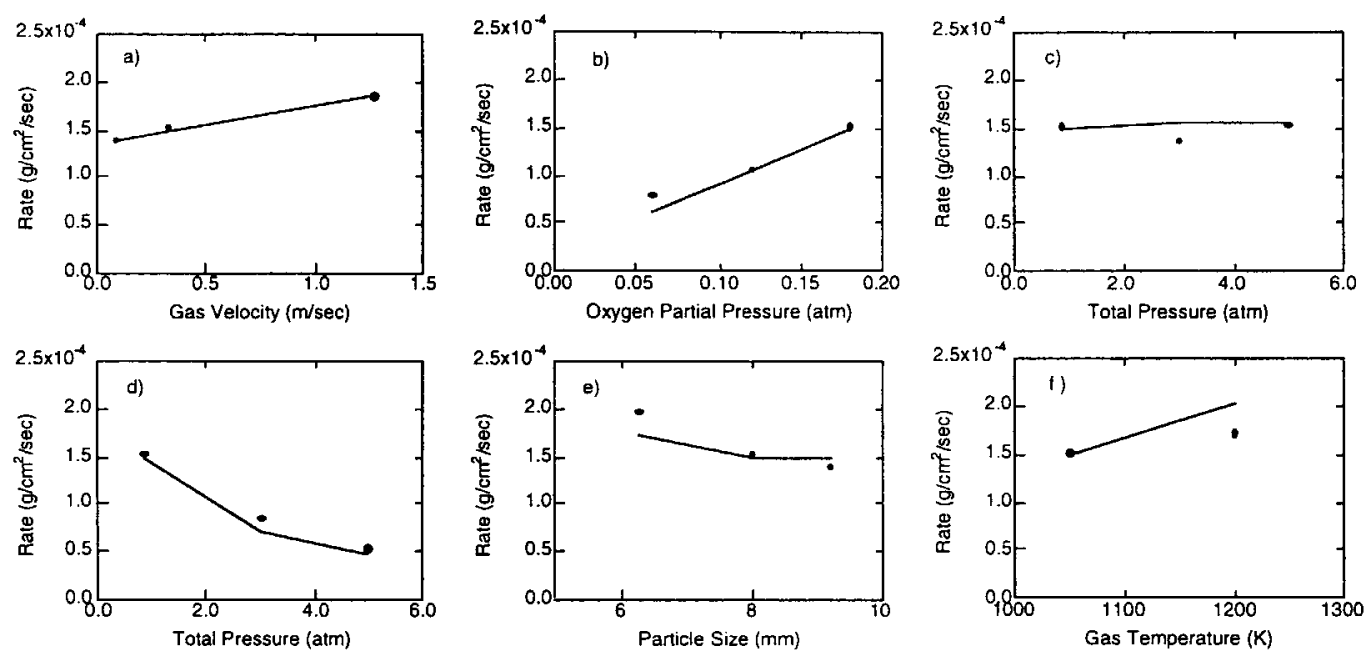

FIG. 2. Comparison of HP-CBK predictions of reaction rate with large coal char particle data [23] as a function of (a) $V_{\mathrm{g}}$, (b) $\left(P_{\text {tot }}=0.85 \mathrm{~atm}\right),(\mathrm{c}) P_{\text {tot }}\left(y_{\mathrm{O}_{2}}=21 \%\right)$, (d) $P_{\text {tot }}\left(P_{\mathrm{O}_{2}}=0.18 \mathrm{~atm}\right),(\mathrm{e}) d_{\mathrm{p}}$, (f) $T_{\mathrm{g}}$.

(see Ref. [15]), ignoring radial gradients inside the particle for this initial investigation.

Kinetic parameters $\left(A_{1}, E_{1}, A, E\right)$ and pore structure parameters $\left(r_{\mathrm{pl}}, r_{\mathrm{p} 2}, \varepsilon_{\mathrm{M}}\right)$ were adjusted to minimize the difference between the predictions and the data. Three observations were made:

1. The best fit used an intrinsic Langmuir rate equation that reduced to a zeroth order reaction.

2. The diffusivity contributed from micropores can be neglected compared to the diffusivity contributed from macropores.

3. Macropores are large enough so that Knudsen diffusivity can be neglected compared to molecular diffusivity.

The first finding means that $K P_{\text {os }}$ is much greater than 1 so that the Langmuir rate equation reduced to the zeroth order rate equation:

$$
\begin{aligned}
r_{\text {in }}^{\prime \prime} & =k_{1} P_{\mathrm{os}} /\left(1+K P_{\mathrm{os}}\right) \approx k_{1} P_{\mathrm{os}} /\left(K P_{\mathrm{os}}\right) \\
& =k_{1} / K=k_{0}=A_{0} e^{-\left(E_{0} / R T\right)}
\end{aligned}
$$

Therefore, the absolute values of $k_{1}$ and $K$ could not be determined, but their ratio $k_{1} / K=k_{0}$ was determined. The intrinsic zeroth order kinetics implied an apparent order of 0.5 in zone II, which is repeatedly observed [1] or assumed [15] for high temperature char oxidation. The second and third findings mean that the effective diffusivity is only determined by the macroporosity $\left(\varepsilon_{\mathrm{M}}\right)$ :

$$
D_{\mathrm{e}}=\varepsilon_{\mathrm{M}}^{2} D_{\mathrm{O}_{2}, \mathrm{~N}_{2}}=1.523 \times 10^{-5} T^{1.67} \varepsilon_{\mathrm{M}}^{2} / P
$$

These three findings greatly simplified the model and reduced the number of adjustable parameters to three: $A_{0}, E_{0}$, and $\varepsilon_{\mathrm{M}}$. The best-fit kinetic and pore structure parameters are listed in Table 1, and comparisons between calculations and measurements are shown in Fig. 2. The HP-CBK model was able to quantitatively explain the effects of all six experimental variables: total pressure, oxygen partial pressure, oxygen mole fraction, gas velocity, gas temperature, and particle size with a standard deviation of $14 \%$ and a maximum error of $22 \%$.

\section{Pulverized Coal Char Experiments}

Monson et al. conducted char oxidation experiments on a $70 \mu \mathrm{m}$ Utah coal char at $1,5,10$, and 15 atm total pressure $[3,4]$. Chars were prepared in the $\mathrm{HPCP}$ furnace in an $\mathrm{N}_{2}$ environment at atmospheric pressure, wall and gas temperatures of $1500 \mathrm{~K}$, and a residence time of $300 \mathrm{~ms}$. In the char oxidation experiments, reactor temperatures were varied between 1000 and $1500 \mathrm{~K}$, with $5 \%$ to $21 \%$ oxygen in the bulk gas, resulting in average particle temperatures up to $2100 \mathrm{~K}$ and burnouts from $15 \%$ to $96 \%$ (daf).

\section{Approach}

Two injection probes, one cooled and the other uncooled, were used during the tests. Because of the large heat loss and more particle dispersion associated with the cooled probe, only the experiments using the uncooled probe were considered in this study.

In these experiments, the temperatures and velocities of the particles were measured using a twocolor pyrometer immediately before the particles entered the collection probe. The reported particle temperatures seem unreasonably high and do not 


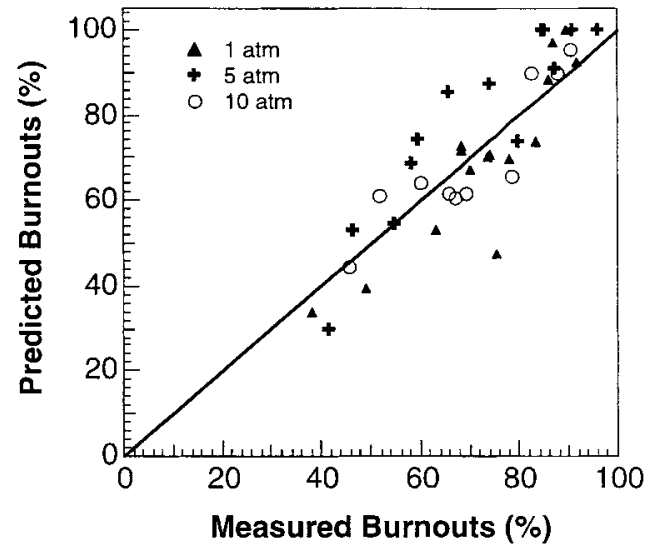

FIG. 3. Comparison of HP-CBK predictions of carbon burnouts with pulverized coal char data [4] as a function of total pressure, oxygen mole fraction, gas temperature, wall temperature, and residence time.

permit balance of the particle energy equation. It is likely that many of the actual particle temperatures were below the temperature measurement threshold, and only a few nonrepresentative particles were measured. Such errors were shown for other char oxidation experiments by Fletcher and Hardesty [28]. Therefore, the measured particle temperatures were not used. Instead, a $\mathrm{CO} / \mathrm{CO}_{2}$ product ratio was assumed and the particle temperatures were calculated by the model. The particle burning mode parameter [15] was held constant at 0.2 (i.e., $\rho / \rho_{0}=$ $\left.\left(\mathrm{m} / \mathrm{m}_{0}\right)^{0.2}\right)$. The carbon burnout (daf) of the collected particles was determined following the contents of three tracers (ash, Ti, and Al). For each test, burnout values were calculated using each of the tracers. In almost every case, the three values agreed within a few percent, promoting confidence in the determination of burnout.

The measured burnout data were used to evaluate the model. Residence times were calculated from the measured particle velocities and the gas temperatures, assuming that the gas and particle velocities were equal. Non-uniform wall temperatures were correlated using a quadratic equation [14]. The measured centerline gas temperatures varied mainly with total pressure [29] and were used directly in the model.

The HP-CBK model was used to predict the burnouts for all the experiments conducted at $1,5,10$, using the above-mentioned gas temperature and wall temperature profiles. The experiments conducted at $15 \mathrm{~atm}$ had extremely low wall temperatures (e.g., $631 \mathrm{~K}$ ) and low gas temperatures (e.g., $987 \mathrm{~K}$ ), and hence were not considered due to ignition problems.
Results

In minimizing the standard deviation of model predictions, it was found that the first two observations made in modeling the large particle experiments of Mathias [24] were true again for these pulverized char oxidation data [4].

The kinetic and pore structure parameters used in this study are listed in Table 1. The best-fit calculations of burnouts from the HP-CBK are compared with the experimental data in Fig. 3. The HP-CBK model was able to predict particle burnouts with a standard deviation of $14 \%$ and a maximum error of $36 \%$.

\section{Summary and Conclusions}

The Langmuir rate equation, when used with the appropriate effectiveness factor, seems to be satisfactory for modeling char oxidation over a wide range of temperature and gas pressure. The reaction order of the carbon-oxygen reaction seems to decrease with increased particle temperature at constant oxygen concentration, which is supported by experimental data $[23,25]$. In modeling the data by Mathias [24] and Monson [4], it was found that the Langmuir rate equation reduced to an intrinsic zeroth order equation for both cases. The intrinsic zeroth order equation implies an apparent order of 0.5 in zone II, in agreement with many observations $[1,15]$. This suggests that an intrinsic $m$ th order $(m$ $=0$ ) is adequate for modeling char oxidation rates as a function of total pressure at high temperatures, although a global $n$th order rate equation has been shown to be inadequate for that task. However, an intrinsic $m$ th order rate equation is inadequate for modeling char oxidation over a wide range of particle temperature since the intrinsic reaction order is typically non-zero at low temperatures and may change with temperature [23].

In the specific cases examined in this study, micropores can be neglected compared to macropores in modeling the effective diffusivity in the porous char matrix.

Since experimental data at high pressures and temperatures are so limited, the correlations between kinetic parameters (activation energies and pre-exponential factors) and measurable char properties are not yet possible. However, it is thought that the approach used in the HP-CBK model is promising and may eventually yield coal-general correlations.

\section{Nomenclature}

A, $A_{1}, A_{0}$ pre-exponential factors for $K, k_{1}$, and $k_{0}$, respectively

B burnout, dry ash-free basis 
$D_{\mathrm{M}}, D_{\mu} \quad$ combined diffusivity in macro- and micropores, respectively, $\mathrm{cm}^{2} / \mathrm{s}$

$D_{\mathrm{AB}} \quad$ molecular diffusivity, $\mathrm{cm}^{2} / \mathrm{s}$

$D_{\mathrm{e}} \quad$ effective diffusivity, $\mathrm{cm}^{2} / \mathrm{s}$

$D_{\mathrm{K}} \quad$ Knudsen diffusivity, $\mathrm{cm}^{2} / \mathrm{s}$

$E, E_{1}, E_{0}$ activation energies for $K, k_{1}$ and $k_{0}$, respectively, $\mathrm{kcal} / \mathrm{mol}$

$K$ a kinetic parameter, $K=A \exp (-E /$ $\left.R T_{\mathrm{p}}\right), \mathrm{atm}^{-1}$

$m \quad$ mass of particle

$M_{\mathrm{c}} \quad$ molecular weight of carbon

$M_{\mathrm{T}} \quad$ general (Thiele) modulus

$\mathrm{Nu} \quad$ Nusselt number

$P, P_{\text {tot }} \quad$ total gas pressure, atm

$P_{\mathrm{O}_{2}} \quad$ oxygen partial pressure, atm

$\mathrm{Pr}_{\mathrm{O}} \quad$ Prandtl number

$R \quad$ gas constant

Re Reynolds number

Sc Schmidt number

$S_{\mathrm{e}} \quad$ external surface area of a particle, $\mathrm{cm}^{2}$

Sh Sherwood number

$T_{\mathrm{g}} \quad$ gas temperature, $\mathrm{K}$

$T_{\mathrm{p}} \quad$ particle temperature, $\mathrm{K}$

$U$ unburned fraction of the carbonaceous material, equal to $(1-\mathrm{B})$

$V_{\mathrm{g}} \quad$ gas velocity, $\mathrm{m} / \mathrm{s}$

$V_{\mathrm{p}} \quad$ volume of a char particle

$d_{\mathrm{p}}^{\mathrm{p}} \quad$ particle size, $\mathrm{cm}$

$k_{1} \quad$ a kinetic parameter in equation $2, k_{1}=$ $A_{1} \exp \left(-E_{1} / R T_{\mathrm{p}}\right), \mathrm{mol} /\left(\mathrm{cm}^{3}\right.$ atm s$)$

$k_{1}^{\prime} \quad$ a variation of $k_{1}$, mol C/(g C remaining)/ $\mathrm{s}$

$k_{0} \quad k_{1} / K, k_{0}=A_{0} \exp \left(-E_{0} / R T_{\mathrm{p}}\right)$

$q \quad$ reaction rate per unit external surface area of particle, $\mathrm{g} \mathrm{C} / \mathrm{cm}^{2} / \mathrm{s}$

$r_{\text {in }}^{\prime \prime \prime} \quad$ intrinsic reaction rate per unit volume of particle, $\mathrm{mol} \mathrm{C} / \mathrm{cm}^{3} / \mathrm{s}$

$r_{\mathrm{obs}}^{\prime \prime \prime} \quad$ observed reaction rate per unit volume of particle, $\mathrm{mol} \mathrm{C} / \mathrm{cm}^{3} / \mathrm{s}$

$r_{\mathrm{p}} \quad$ pore radius, $\mathrm{nm}$

$y_{\mathrm{O}_{2}} \quad$ oxygen mole fraction

Greek symbols

$\alpha \quad$ power index of the normalized densitydiameter relationship

$\chi \quad$ actual rate over the maximum rate in boundary layer diffusion

$\varepsilon \quad$ second effectiveness factor

$\varepsilon, \varepsilon_{\mathrm{M}} \quad$ total porosity and macroporosity

$\eta \quad$ effectiveness factor

$v_{\mathrm{o}} \quad$ stoichiometric factor of oxygen for each mole carbon consumed

$\rho \quad$ particle density, $\mathrm{g} / \mathrm{cm}^{3}$

\section{Subscripts}

in intrinsic

$\max$ maximum

o initial obs observed

og oxygen in bulk steam

os oxygen at external surface

rxn reaction

\section{Acknowledgments}

Financial support was provided by the Advanced Combustion Engineering Research Center (ACERC) at Brigham Young University (BYU). Thanks are given to J. A. Mathias for useful discussions on his experiments, thesis [24] and a paper presented at the Spring 1998 Central States Meeting, pp. 65-71 (High Pressure Oxidation Rates of Large Char Particles: Dependence of Reaction Rates on In Situ Heat Treatment, Mathias, J. A., Essenhigh, R. H., and Radulovich, P. T.). The authors would like to give special acknowledgment to Dr. R. H. Hurt for providing the source code of the CBK model and for useful discussions.

\section{REFERENCES}

1. Smith, I. W., Proc. Combust. Inst. 11:1045-1065 (1982).

2. Hurt, R. H., and Mitchell, R. E., Proc. Combust. Inst. 24:1243-1250.

3. Monson, C. R., Germane, G. J., Blackham, A. U., and Smoot, L. D., Combust. Flame 100:669-683 (1995).

4. Monson, C. R., "Char Oxidation at Elevated Pressure," Ph.D. dissertation, Brigham Young University, Provo, UT, 1992.

5. Essenhigh, R. H., and Mescher, A. M., Proc. Combust. Inst. 26:3085-3094 (1996).

6. Essenhigh, R. H., in Chemistry of Coal Utilization: Second Suppl. Volume (M. A. Elliott, ed.), Wiley, New York, 1981, pp. 1153-1312.

7. Essenhigh, R. H., Energy Fuels 5:41 (1991).

8. Du, Z., Sarofim, A. F., Longwell, J. P., and Mims, C. A., Energy Fuels 5:214-221 (1991).

9. Laurendeau, N. M., Prog. Energy Combust. Sci. 4:221-270 (1978).

10. Essenhigh, R. H., Proc. Combust. Inst. 22:89-96 (1988).

11. Essenhigh, R. H., Förtsch, D., and Klimesh, H. E., Energy Fuels 13:955-960 (1999).

12. Bischoff, K. B., AIChE J. 11:351-355 (1965).

13. Hong, J., Hecker, W. C., and Fletcher, T. H., Energy Fuels 14:663-670 (2000).

14. Hong, J., "Modeling Char Oxidation as a Function of Pressure Using an Intrinsic Langmuir Rate Equation," Ph.D. dissertation, Brigham Young University, Provo, UT, 2000 .

15. Mitchell, R. E., Hurt, R. H., Baxter, L. L., and Hardesty, D. R., Sandia report SAND92-8208.

16. Hurt, R. H., Sun, J. K., and Lunden, M., Combust. Flame 113:181-197 (1998).

17. Bird, R. B., Stewart, W. R., and Lightfoot, E. N., Transport Phenomena, John Wiley and Sons, New York, 1960. 
18. Frank-Kamenetskii, D. A., Diffusion and Heat Transfer in Chemical Kinetics, Plenum Press, New York, 1969.

19. Smith, J. M., Chemical Engineering Kinetics, McGraw Hill, New York, 1981.

20. Mitchell, R. E., Sandia report SAND79-8236.

21. Wakao, N., and Smith, J. M., Chem. Eng. Sci. 17:825 (1962).

22. Wakao, N., and Smith, J. M., Ind. Eng. Chem. Fundam. 3:123 (1964).

23. Ranish, J. M., and Walker Jr., P. L., Carbon 31:135 (1993).
24. Mathias, J. A., "High Pressure Oxidation Rates for Large Particles,” M.S. thesis, Brigham Young University, Provo, UT, 1996.

25. Banin V., Moors, R., and Veefkind, B., Fuel 76:945949 (1997).

26. Bateman, K. J., Germane, G. J., Smoot, L. D., and Eatough, C. N., Energy Fuels 9:295-301 (1995).

27. Hurt, R. H., and Davis, K. A., Proc. Combust. Inst. 25:561-568 (1994).

28. Fletcher, T. H., and Hardesty, D. R., Sandia report SAND92-8209.

29. Monson, C. R., and Germane, J. G., Energy Fuels 7:928-936 (1993).

\section{COMMENTS}

Gui-su Lin, University of Newcastle, Australia. In your calculation of effective diffusivity, both Knudsen diffusion and bulk diffusion are considered. However, for char combustion at high temperatures, several other calculations have been presented, in some of which only macropores are considered. These calculations reflect the different pressure effect which is important in your work. So, how do you think that different calculation methods affect your prediction?

Author's Reply. In general, both micropores and macropores should be considered. In some cases, only macropores are considered because the contribution to the effective diffusivity from the micropores is negligible according to model calculations. The micropores can be neglected when (1) the micropore size is very small, (2) the microporosity is very low, or (3) factors are combined. In general, both Knudsen diffusion and bulk diffusion should be considered. Again, in some cases you will find that one of these two mechanisms can be neglected. For example, when the pore size is large enough, the Knudsen diffusion can be neglected.

Christopher Shaddix, Sandia National Laboratories, USA. In this paper, the analysis performed by Monson et al. (Refs. [3,4] in this paper) is used to reject the possible applicability of a global $n$ th-order rate equation. Yet, I believe that conclusion was based, at least in part, on the particle temperature measurements that were performed-measurements that you reject later in the paper as unphysical. Are you certain that an $n$ th-order approach could not predict the pulverized coal burnout data as well as the more complicated approach you have adopted here?

Author's Reply. In this study, the particle temperature measurements were rejected since many of them were unfortunately too high and did not allow energy balance. Instead, a $\mathrm{CO} / \mathrm{CO}_{2}$ ratio expression was adopted to calculate particle temperatures.
This paper showed that the Langmuir rate equation reduced to an intrinsic zeroth order rate equation, which implied a half order under zone II conditions. However, this does not mean a global half-order rate equation is generally adequate since (1) the form of the effectiveness factor for the Langmuir rate expression is different from that of the $n$ th-order reaction; (2) in general, a global $n$th order rate equation is inadequate to capture the changes of activation energy, reaction order, and reaction rate during the transition from zone I to zone II; (3) the intrinsic order of zero is just a special case of the Langmuir rate equation and is not applicable to other conditions. Our attempts to empirically fit the Monson data with a global $n$th order model required dividing the rate by the total pressure raised to a fractional order. The use of the global $n$th order approach was therefore not pursued.

This paper shows that the Langmuir rate equation, when used with the effectiveness factor, is much more flexible and capable of capturing the complex trends in activation energy, reaction order, and reaction rate.

Stephen Niksa, Niksa Energy Associates, USA. The rate of homogeneous oxidation of $\mathrm{CO}$ to $\mathrm{CO}_{2}$ will increase for progressively higher pressures. Moreover, your data evaluations include fairly large particles, which would probably support envelope CO flames even at atmospheric pressure. How did you account for the influence of homogeneous CO oxidation in your analysis of data?

Author's Reply. The $\mathrm{CO} / \mathrm{CO}_{2}$ ratio expression can be modified to include effects of total pressure and/or oxygen partial pressure with ease. However, we believe that more experimental data are needed to quantitatively establish the effects of pressure on the $\mathrm{CO} / \mathrm{CO}_{2}$ ratio. The pressure effects on the $\mathrm{CO} / \mathrm{CO}_{2}$ ratio were not included in order to limit the number of parameters in the model. 
The effects of an envelope CO flame have not yet been considered in this modeling effort. It may be possible that this effect is important, especially since flame thickness tends to decrease at high pressures due to increased concentrations. The smaller flame thickness may therefore permit a flame in the boundary layer. Internal temperature gradients should also be considered in the large particle experiments, indicating the need for data on the effective thermal conductivity of porous coal chars. 